\title{
Multi objective optimization of wear behaviour of Aluminum MMCs using Grey-Taguchi method
}

\author{
Poovalingam Muthu ${ }^{*}$ \\ Mechanical Engineering Department, University College of Engineering, Anna University, Ramanathapuram 623513 , \\ Tamilnadu, India
}

Received: 15 December 2019 / Accepted: 18 March 2020

\begin{abstract}
In recent years, metal matrix composite (MMCs) have been receiving worldwide attention on account of their superior strength-to-weight ratio and stiffness. Among the several classes of composite materials, Aluminium matrix ceramic reinforcement composites have attracted increasing attention due to their unique properties such as better specific strength, specific stiffness, wear resistance, excellent corrosion resistance, high elastic modulus and light weight. The aim of the present investigation is to optimize the dry sliding wear parameters of Aluminum LM25 matrix reinforced with silicon carbide (SiC) (5 wt.\%) and Copper $(\mathrm{Cu})$ (3 wt.\%) using Taguchi based grey relational analysis. In this work, the composite is prepared using stir casting method. The specimens are prepared according to ASTM standard. Using pin-on-disc apparatus, wear tests are conducted as per Taguchi's L9 orthogonal array and optimum wear parameters are identified with an objective to minimise the wear rate and coefficient of friction based on the grey relational grade. The effect of parameters on the wear rate and coefficient of friction was determined using Analysis of variance (ANOVA). Finally, the experimental results were verified using confirmation tests and the SEM analysis was carried out to study the wear mechanism.
\end{abstract}

Keywords: Aluminium-metal matrix composite / optimization / grey relational analysis / ANOVA

\section{Introduction}

Due to the advancement in science and technology, there is a demand of advanced engineering materials in the field of automotive and aerospace areas. These area demands materials having better mechanical and tribological properties than the conventional materials. In recent years, metal matrix composite (MMCs) are playing an important role in various applications due to their high temperature resistance and strength [1]. The MMC is the combination of two or more constituents in which one is matrix and other is reinforcements. At present, aluminium based metal matrix composites are widely used in many engineering applications because of their improved wear resistance, low density, enhanced strength and stiffness.

The tribological parameters such as applied load (Prasad et al. [2], Bai et al. [3] sliding speed (Lee et al. [4], Sannino et al. [5]), and percent of fly ash control the friction and wear performance. Sreenivasan et al. [6] reported the wear behaviour aluminium reinforced with $\mathrm{TiB}_{2}$ that the increase in TiB2 results in decrease of the

\footnotetext{
* e-mail: vpmuthu2001@yahoo.com
}

wear rate and the increase in applied load results in increase of the wear rate of the MMCs. However, it was decreased with increase in speed. Gaitonde et al. [7], Ravi Kumar et al. [8], and Zhang et al. [9] reported that the wear resistance of MMCs depends upon shape of the particle, distribution of reinforcement material and volume fraction. Shanawaz Patil et al. [10] concluded that the wear rate for the metal matrix composite increases with increase in speed for a given constant load and time. Ravi et al. [11] conducted the tribological tests on Al6061 reinforced with redmud and reported that red mud particles in Al-6061 increase the hardness and coefficient of friction decrease with increase in weight percent of red mud reinforcement. Amuthakkannan et al. [12] investigated the wear rate of the composites with parameters such as percent of reinforcement, Sliding velocity and Normal load using Grey relation analysis. They found that all the parameters taken for the wear study are significant and the most significant parameter was on Normal load and the optimized parameters are Sliding velocity $(\mathrm{m} / \mathrm{sec})$ of 2 , Normal load (N) of 20, Reinforcement of basalt fiber (percent) of 10. Arulraj et al. [13] investigated the tribological

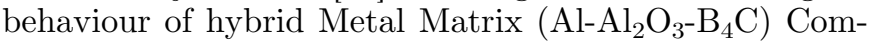
posite. They concluded that the applied load and sliding 
velocity were important parameters followed by time duration on wear rate. Bhaskar et al. [14] investigated the wear behaviour of Al2024 reinforced with beryl particulate MMC's. They find that wear rate and coefficient of friction of Al2024 and the composites decreases with increase in sliding speed up to $3 \mathrm{~m} / \mathrm{s}$ for a load of $40 \mathrm{~N}$, after that wear rate and coefficient of friction slightly increases as the sliding speed increases. Ahemad et al. [15] studied the tribological behaviour of LM25 reinforcement with $\mathrm{SiC}$ that the wear rate varies linearly with normal load. Also, they Narayan et al. [16] studied the wear behaviour of LM4 (Al-Si5Cu3)-T6/LM6 (Al-Si12)-M using Taguchi Approach. They concluded that the wear rate of LM6-M alloy increases with increase in percentage of silicon than LM4-T6 alloy. Akhlaghi et al. [17,18] studied the tribological behaviour of $\mathrm{SiC}$ and $\mathrm{Gr}$ reinforced Al6061. They find that the wear rate of the prepared composite increases with increase of SiC. Sanjeev Das et al. [19] studied the abrasive wear of $\mathrm{Al}-\mathrm{Cu}$ alloy with alumina and Zircon sand particles and concluded that wear resistance of the composite increases with the addition of alumina and zircon particles. Ranganath et al. [20] investigated that the wear resistances of Al6061 reinforced with garnet particles. They reported that the wear rate of Garnet particle reinforced composites is more than the unreinforced alloy specimens and the wear rate decreased with increasing garnet content. Also they found that the increase in applied load increases the wear rate of the composites as well as the matrix alloy. Umanath et al. [21] investigated the wear behaviour of Al6061reinforced with $\mathrm{SiC}$ and $\mathrm{Al} 2 \mathrm{O} 3$ hybrid metal matrix composites. They reported that the wear resistance of the 5 percent hybrid composite is poorer than that of the 15 percent composite. In the present investigation, an attempt has been made to determine best parameters such as load, sliding velocity and sliding distance to optimize the wear rate and coefficient of friction (COF) simultaneously using Grey Taguchi method. The optimized parameters were then verified through a confirmation experiment. Finally, the worn out surfaces and wear mechanism of the matrix composites were studied using SEM.

\section{Experimental procedures}

\subsection{Materials and methods}

In this investigation, LM25 was used as a matrix material. Silicon carbide and copper were used as reinforcements. The chemical composition of the LM25 in weight percent is given in Table 1 . The silicon carbide particle size ranges from 30 to 40 microns. The composite with $5 \mathrm{wt} . \%$ of $\mathrm{SiC}$ particles and 3 percent $\mathrm{Cu}$ was fabricated by the mechanical stir casting technique. Weighed amount of LM25 was melted at $850{ }^{\circ} \mathrm{C}$ in an electric resistance furnace using a graphite crucible. Before adding $\mathrm{SiC}$ and $\mathrm{Cu}$ particulates to LM25, they were preheated to a temperature of about $350{ }^{\circ} \mathrm{C}$. Then they were added to the molten metal at $850{ }^{\circ} \mathrm{C}$ and stirred continuously for uniform distribution. The stirring was done at $750 \mathrm{rpm}$ for 7-9 min. Then the molten material was poured into a permanent metallic mould and allowed to solidify. After solidification,
Table 1. Chemical composition of LM25 (in weight \%).

\begin{tabular}{ll}
\hline Composition & Percentage (\%) \\
\hline $\mathrm{Si}$ & $6.5-7.5$ \\
$\mathrm{Fe}$ & 0.5 \\
$\mathrm{Cu}$ & 0.1 \\
$\mathrm{Mn}$ & 0.3 \\
$\mathrm{Mg}$ & $0.2-0.6$ \\
$\mathrm{~Pb}$ & 0.1 \\
$\mathrm{Ni}$ & 0.1 \\
$\mathrm{Zn}$ & 0.1 \\
$\mathrm{Sn}$ & 0.05 \\
$\mathrm{Ti}$ & 0.2 \\
$\mathrm{Al}$ & balance \\
\hline
\end{tabular}

Table 2. Input process parameters with their values at three levels.

\begin{tabular}{llll}
\hline Factors & Level 1 & Level 2 & Level 3 \\
\hline Load $(\mathrm{N})$ & 10 & 20 & 30 \\
Sliding velocity $(\mathrm{m} / \mathrm{s})$ & 2.0 & 2.4 & 2.7 \\
Sliding distance $(\mathrm{m})$ & 1000 & 1150 & 1300 \\
\hline
\end{tabular}

the cast samples were taken away from the mould and machined to a dimensions of $10 \mathrm{~mm}$ in diameter and $30 \mathrm{~mm}$ in length as per ASTM G99-95 (2010).

\subsection{Plan of experiment}

The Taguchi design method was developed by Dr. Genichi Taguchi. It is a simple and robust technique for optimizing the process parameters. In this method, load, sliding velocity and sliding distance are taken as main process parameters input parameters and the experiment is performed as per L9 orthogonal array. The levels of various input process parameters according to the L9 orthogonal array for the experiments are shown in Table 2.

The signal-to-noise ratio is a logarithmic function used to optimize the process or product design, minimizing the variability. In general, signal to noise $(\mathrm{S} / \mathrm{N})$ ratio $(\eta, \mathrm{dB})$ represents quality characteristics for the observed data in the Taguchi design of experiments. There are 3 signal-tonoise ratios of common interest for optimization of Static Problems. They are lower-the-better, higher-the-better and nominal-the better. The $\mathrm{S} / \mathrm{N}$ ratio with lower-thebetter characteristics (wear rate, coefficient of friction etc.,) can be calculated using equation (1)

$$
\eta_{i j}=-10 \log \left(\frac{1}{n}\right) \sum_{j=1}^{n} y_{i j}^{2}
$$

where $\eta_{i j}$ is the $j^{\text {th }} \mathrm{S} / \mathrm{N}$ ratio of the $i^{\text {th }}$ experiment, $y_{i j}$ is the $i^{\text {th }}$ experiment at the $j^{\text {th }}$ test, $n$ is the total number of the tests. 
Table 3. Experimental plan and results.

\begin{tabular}{lllllll}
\hline Ex. No & Load $(\mathrm{N})$ & $\begin{array}{l}\text { Sliding velocity } \\
(\mathrm{m} / \mathrm{s})\end{array}$ & $\begin{array}{l}\text { Sliding distance } \\
(\mathrm{m})\end{array}$ & $\begin{array}{l}\text { Density } \\
\mathrm{g} / \mathrm{mm}^{3}\end{array}$ & $\begin{array}{l}\text { Initial } \\
\text { mass }(\mathrm{g})\end{array}$ & $\begin{array}{l}\text { Final } \\
\text { mass }(\mathrm{g})\end{array}$ \\
\hline 1 & 10 & 2 & 1000 & 0.002688 & 6.360864 & 6.351364 \\
2 & 10 & 2.4 & 1150 & 0.002688 & 6.370356 & 6.358111 \\
3 & 10 & 2.7 & 1300 & 0.002688 & 6.430784 & 6.41875 \\
4 & 20 & 2 & 1150 & 0.002688 & 6.440568 & 6.431701 \\
5 & 20 & 2.4 & 1300 & 0.002688 & 6.150237 & 6.138626 \\
6 & 20 & 2.7 & 1000 & 0.002688 & 6.400665 & 6.382087 \\
7 & 30 & 2 & 1300 & 0.002688 & 6.090467 & 6.050778 \\
8 & 30 & 2.4 & 1000 & 0.002688 & 6.265047 & 6.217758 \\
9 & 30 & 2.7 & 1150 & 0.002688 & 6.390743 & 6.373643 \\
\hline
\end{tabular}

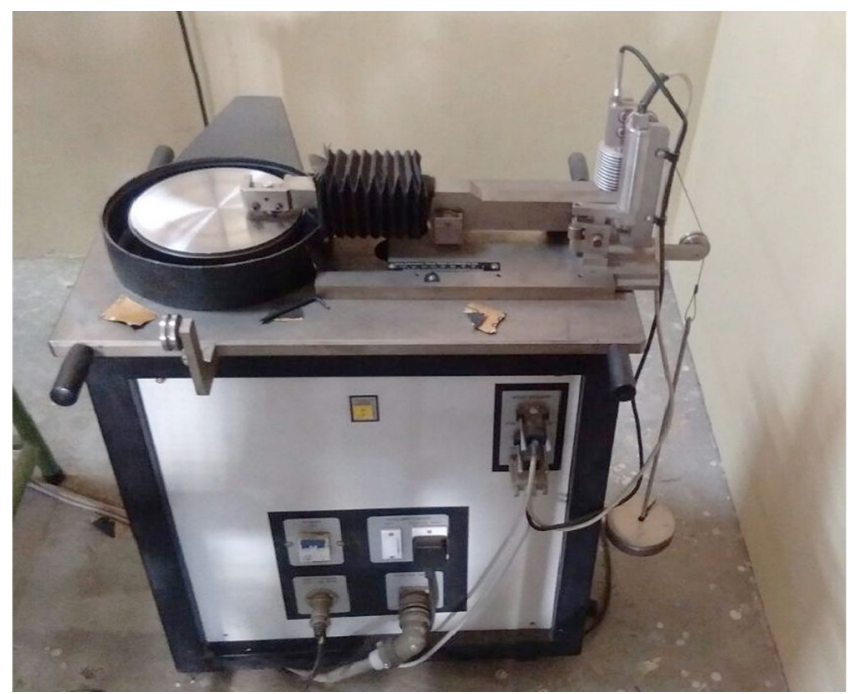

Fig. 1. Pin on disc apparatus.

\subsection{Wear test}

The pin on disc apparatus (Ducom, model No: ED-201, Bangalore, India) (see Fig. 1) is used to evaluate the wear rate and coefficient of friction of the specimens.

Tests were conducted as per L9 orthogonal array under dry sliding conditions as per ASTM G99-95 (2010) at a room temperature. The counter-face disc is made of EN-31 steel with the hardness of $62 \mathrm{HRC}$. Initially, the test samples were polished metallographically. The initial weight of the specimen was measured using a single pan electronic weighing machine with least count of $0.0001 \mathrm{~g}$. Then the test the pin was pressed against the counterpart rotating against EN-31 steel with the hardness of 62 HRC. After the test, the specimens were removed, cleaned with acetone, dried and the specimen was weighed to find the final weight of the specimen. From the initial and final weight of the specimen the initial and final volume of the specimen are calculated using the equations (2) and (3) and is shown in Table 3 .

Initial volume of the specimen

$$
=\frac{\text { Initial weight of the specimen }}{\text { Density of the specimen }}
$$

Final volume of the specimen

$$
=\frac{\text { Final weight of the specimen }}{\text { Density of the specimen }}
$$

Then final volume loss of the specimen, wear rate and coefficient of friction are calculated using equations (4)-(6) and is shown in Table 4.

$$
\begin{aligned}
& \text { Volume loss of the specimen } \\
& \text { = Final volume of the specimen } \\
& \text {-Initial volume of the specimen }
\end{aligned}
$$

$$
\text { Wear rate }=\frac{\text { Volume loss }}{\text { Sliding distance }} \frac{\mathrm{mm}^{3}}{\mathrm{~m}}
$$

$$
\text { Coefficient of friction }(\mathrm{COF})=\frac{\text { Frictional force }}{\text { Normal force }}
$$

\subsection{Grey relational analysis (GRA)}

Single performance characteristics can be easily optimized by Taguchi method. However, it is a challenging task for analyzing and solving multi performance characteristics. GRA is one of the techniques used for optimization of control factors having multi-performances. The various steps of GRA technique are:

\section{Step 1: Normalization}

In this step, measured features of quality characteristics i.e., wear rate and coefficient of friction are first normalized ranging from zero to one. This process is known as Grey relational generation. Three approaches are used for normalization. If the target value of original sequence is 
Table 4. Wear rate and coefficient of friction.

\begin{tabular}{llllllllll}
\hline $\begin{array}{l}\text { Ex. } \\
\text { No }\end{array}$ & $\begin{array}{l}\text { Load } \\
(\mathrm{N})\end{array}$ & $\begin{array}{l}\text { Sliding } \\
\text { velocity } \\
(\mathrm{m} / \mathrm{s})\end{array}$ & $\begin{array}{l}\text { Sliding } \\
\text { distance } \\
(\mathrm{m})\end{array}$ & $\begin{array}{l}\text { Initial } \\
\text { volume } \\
\left(\mathrm{mm}^{3}\right)\end{array}$ & $\begin{array}{l}\text { Final } \\
\text { volume } \\
\left(\mathrm{mm}^{3}\right)\end{array}$ & $\begin{array}{l}\text { Volume } \\
\text { loss }\left(\mathrm{mm}^{3}\right)\end{array}$ & $\begin{array}{l}\text { Frictional } \\
\text { force }(\mathrm{N})\end{array}$ & $\begin{array}{l}\text { Wear rate } \\
\left(\mathrm{mm}^{3} / \mathrm{m}\right)\end{array}$ & $\begin{array}{l}\text { Coefficient } \\
\text { of friction }\end{array}$ \\
\hline 1 & 10 & 2 & 1000 & 2366.393 & 2362.859 & 3.534226 & 3.52 & 0.003534 & 0.3521 \\
2 & 10 & 2.4 & 1150 & 2369.924 & 2365.369 & 4.555432 & 4.03 & 0.003961 & 0.4032 \\
3 & 10 & 2.7 & 1300 & 2392.405 & 2387.928 & 4.476935 & 3.78 & 0.003444 & 0.3781 \\
4 & 20 & 2 & 1150 & 2396.045 & 2392.746 & 3.298735 & 2.21 & 0.002868 & 0.1105 \\
5 & 20 & 2.4 & 1300 & 2288.035 & 2283.715 & 4.319568 & 13.52 & 0.003323 & 0.6760 \\
6 & 20 & 2.7 & 1000 & 2381.2 & 2374.288 & 6.911458 & 7.21 & 0.006911 & 0.3605 \\
7 & 30 & 2 & 1300 & 2265.799 & 2251.033 & 14.76525 & 8.47 & 0.011358 & 0.2823 \\
8 & 30 & 2.4 & 1000 & 2330.747 & 2313.154 & 17.59263 & 11.75 & 0.017593 & 0.3916 \\
9 & 30 & 2.7 & 1150 & 2377.509 & 2371.147 & 6.361607 & 11.44 & 0.005532 & 0.3813 \\
\hline
\end{tabular}

infinite, then it has a characteristic of "the-larger-thebetter." The original sequence can be normalized using equation (7)

$$
X_{i}^{*}(k)=\frac{X_{i}^{0}(k)-\min X_{i}^{0}(k)}{\max X_{i}^{0}(k)-\min X_{i}^{0}(k)}
$$

when the lower-the-better characteristic of the original sequence is considered, then the original sequence should be normalized using equation (8)

$$
X_{i}^{*}(k)=\frac{\max X_{i}^{0}(k)-X_{i}^{0}(k)}{\max X_{i}^{0}(k)-\min X_{i}^{0}(k)}
$$

where $X_{i}^{0}(k)$ is the value after the grey relational generation (data preprocessing), $\max X_{i}^{0}(k)$ is the largest value of $X_{i}^{0}(k), \min X_{i}^{0}(k)$ is the smallest value of $X_{i}^{0}(k)$, and $X^{0}$ is the desired value.

Step 2 Calculation of Grey relational coefficient and grey relational grade

In this step, the Grey relational coefficient is calculated to express the relationship between the ideal and the actual experimental results. The grey relational coefficient can be found using equation (9).

$$
\xi_{i}(k)=\frac{\Delta_{\min }+\varsigma \cdot \Delta_{\max }}{\Delta_{o i}(k)+\varsigma \cdot \Delta_{\max }}
$$

where $\zeta(\epsilon 0,1)=$ distinguished coefficient, $\varsigma=0.5$ is generally used. $\xi_{i}(k)$ is grey relational coefficient, $\Delta_{\text {min }}$ is the smallest value of $\Delta_{\mathrm{oi}}(k), \Delta_{\max }$ is the largest value of $\Delta_{\text {oi }}(k), \Delta_{o i}(k)$ is the deviation sequence of the reference sequence $X_{o}^{*}(k)$, and the comparability sequence $X_{i}^{*}(k)$, namely

$$
\begin{gathered}
\Delta_{o i}(k)=\left|X_{o}(k)-X_{i}(k)\right| \\
\Delta_{\max }=\max _{\forall j \varepsilon i} \max _{\forall k}\left|X_{o}^{*}(k)-X_{j}^{*}(k)\right| \\
\Delta_{\min }=\min _{\forall j \varepsilon i} \min _{\forall k}\left|X_{o}^{*}(k)-X_{j}^{*}(k)\right|
\end{gathered}
$$

After obtaining the grey relational coefficient, the Grey relational grade corresponding to each performance characteristic is computed. The grey relational grade can be obtained using equation (10)

$$
\gamma_{i}=\frac{1}{n} \sum_{k=1}^{n} \xi_{i}(k)
$$

where $\gamma_{i}$ is the grey relational grade for the $i$ th experiment and $n$ is the number of performance characteristics.

\section{Results and discussion}

As per grey relational analysis, the experimental results are normalized using equation (4) ranging from zero and then using equation (5), the normalized results are converted into grey relational coefficient to represent the correlation between the desired and actual data. Finally, by averaging the grey relational coefficient, the grey relational grades and their rank are calculated. The $\mathrm{S} / \mathrm{N}$ ratio, Normalized $\mathrm{S} / \mathrm{N}$ ratio of wear rate and $\mathrm{COF}$ along with Grey relational coefficient, Grey relational Grade and Rank are shown in Table 5.

From the value of Grey relational grade in Table 5, the main effects are tabulated in Table 6 and the factor effects are plotted in Figure 2. Since the grey relational grade represents the level of correlation between the reference sequence and the comparability sequence, the greater value of the grey relational grade means that the comparability sequence has a stronger correlation to the reference sequence [22]. In other words, regardless of category of the performance characteristics, a greater grey relational grade value corresponds to better performance [23]. Therefore, the optimal level of the machining parameters is the level with the greatest grey relational grade value. The reference sequence that was selected here had the "smaller-the-better" characteristic. Therefore, the comparability sequence with the larger value of the grey relational grade would induce smaller wear rate and coefficient of friction. Based on this premise, the level that 
Table 5. S/N ratio, Normalized S/N ratio of wear rate and COF along with Grey relational coefficient, Grey relational Grade and Rank.

\begin{tabular}{|c|c|c|c|c|c|c|c|c|}
\hline \multirow[t]{2}{*}{ Ex. No. } & \multicolumn{2}{|c|}{$\mathrm{S} / \mathrm{N}$ ratio } & \multicolumn{2}{|c|}{ Normalized S/N ratio } & \multicolumn{2}{|c|}{ Grey relational coefficient } & \multirow[t]{2}{*}{ Grey relational grade } & \multirow[t]{2}{*}{ Rank } \\
\hline & Wear rate & $\mathrm{COF}$ & Wear rate & $\mathrm{COF}$ & Wear rate & $\mathrm{COF}$ & & \\
\hline 1 & 49.034 & 9.069146 & 0.1151204 & 0.6397029 & 0.36104 & 0.58119 & 0.47111 & 8 \\
\hline 2 & 48.043 & 7.893899 & 0.1780054 & 0.7144087 & 0.37821 & 0.63646 & 0.50734 & 6 \\
\hline 3 & 49.258 & 8.450164 & 0.1008986 & 0.6790492 & 0.35737 & 0.60905 & 0.48321 & 7 \\
\hline 4 & 50.848 & 19.13275 & 0.0000000 & 0.0000000 & 0.33333 & 0.33333 & 0.33333 & 9 \\
\hline 5 & 49.569 & 3.401066 & 0.0811809 & 1.0000000 & 0.35240 & 1 & 0.67620 & 2 \\
\hline 6 & 43.209 & 8.861894 & 0.4848702 & 0.6528771 & 0.49254 & 0.59023 & 0.54139 & 4 \\
\hline 7 & 38.894 & 10.98476 & 0.7587617 & 0.5179347 & 0.67454 & 0.50913 & 0.59183 & 3 \\
\hline 8 & 35.093 & 8.141660 & 1.0000000 & 0.6986595 & 1.00000 & 0.62395 & 0.81197 & 1 \\
\hline 9 & 45.142 & 8.373912 & 0.3621696 & 0.6838962 & 0.43943 & 0.61266 & 0.52605 & 5 \\
\hline
\end{tabular}

Table 6. Main effects on grey grades.

\begin{tabular}{llll}
\hline Level & Load & Sliding velocity & Sliding distance \\
\hline 1 & 0.4872 & 0.4654 & $0.6082^{*}$ \\
2 & 0.5170 & $0.6652^{*}$ & 0.4556 \\
3 & $0.6433^{*}$ & 0.5169 & 0.5838 \\
Delta & 0.1561 & 0.1997 & 0.1526 \\
Rank & 2 & 1 & 3 \\
\hline
\end{tabular}

* Optimum values.

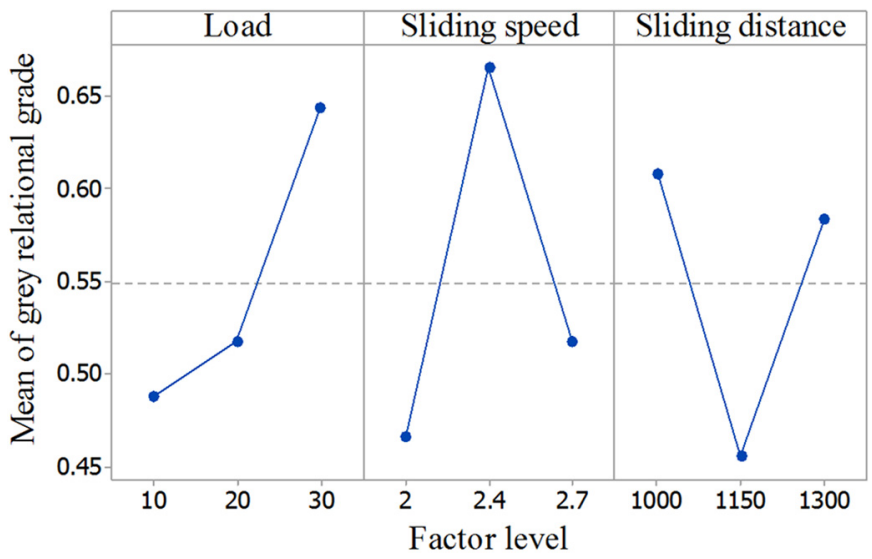

Fig. 2. Effect of grey relational grade.

Table 7. Results of ANOVA on grey grade.

\begin{tabular}{lllllll}
\hline Source & DF & Adj. SS & Adj. MS & F-Value & P-Value & $\%$ C \\
\hline Load & 2 & 0.041197 & 0.020598 & 114.70 & 0.009 & 28.14 \\
Sliding velocity & 2 & 0.064535 & 0.032267 & 179.67 & 0.006 & 44.08 \\
Sliding distance & 2 & 0.040308 & 0.020154 & 112.22 & 0.009 & 27.53 \\
Residual error & 2 & 0.000359 & 0.000180 & & & 0.25 \\
Total & 8 & 0.146399 & & & & 100 \\
\hline
\end{tabular}

gives the largest average response is selected. From Table 6 and Figure 2, the optimum factors for both the wear rate and the coefficient of friction obtained for the hybrid composite are $30 \mathrm{~N}$ load (level 3 ), $2.4 \mathrm{~m} / \mathrm{s}$ sliding velocity (level 2), and $1000 \mathrm{~m}$ sliding distance (level 1) combination.

\subsection{Analysis of variance (ANOVA)}

ANOVA is a statistical method used to interpret the experimental results. In this work, ANOVA is used to analyze the effects of load, sliding velocity and sliding distance on wear. This analysis was carried out for a level of significance of 5 percent, i:e., the level of confidence 95 percent. Table 7 shows the results of the ANOVA for the overall Grey relational grade of MMCs. It is observed from the table that the significant factor is sliding velocity. The sliding velocity (44.08 percent) influences more on the multi-performance characteristics of $\mathrm{LM} 25 / \mathrm{SiC} / \mathrm{Cu}$ hybrid composite followed by load (28.14 percent) and sliding distance (27.53 percent).

\subsection{Confirmation test}

After the optimal level of parameters is identified, a confirmation experiment is carried out to predict and 
Table 8. Results of confirmation experiments.

\begin{tabular}{llll}
\hline & Initial testing parameters & \multicolumn{2}{c}{ Optimum testing parameters } \\
\cline { 3 - 4 } & & Prediction & Experiment \\
\hline Combination of testing & A2B1C2 & A3B2C1 1 \\
Wear rate & 0.002868 & & 0.017593 \\
COF & 0.1105 & & 0.3916 \\
Grey relational grade & 0.333333 & 0.818299111 & 0.811977 \\
\hline
\end{tabular}

verify the improvement of the quality characteristic using the optimal level of design parameters. The predicated gray relational grades of using the optimum level of the dry sliding parameters are calculated using equation (11).

$$
\hat{\gamma}=\gamma_{m}+\sum_{i=1}^{q}\left(\bar{\gamma}_{i}-\gamma_{m}\right)
$$

where $\gamma_{m}$ is the total mean gray relational grade, $\bar{\gamma}_{i}$ is the mean gray relational grade at the optimum level, and ' $q$ ' is the number of main parameters that significantly affect the coefficient of friction and wear rate. Table 8 shows the comparison of the predicted grey relational grade with the actual grey relational grade obtained in the experiment using the optimal process parameters.

From Table 8, it is clear that the optimal data obtained from the confirmation test, which was conducted with the level settings parameters of load $(30 \mathrm{kN})$, Sliding velocity $(2.4 \mathrm{~m} / \mathrm{s})$ and sliding distance $(1000 \mathrm{~m})$ had good agreement with the predicted model. Hence the grey relational analysis based on Taguchi method for the optimization of the multi response problems is a very useful tool for predicting the wear rate and coefficient of friction of LM25/ $\mathrm{SiC} / \mathrm{Cu}$ hybrid metal matrix composites.

\subsection{Surface morphology}

The SEM image of the prepared LM25/SiC/Cu hybrid metal matrix composites is shown in Figure 3. It indicates the nearly uniform distribution of the reinforcement particles in the composite.

After conducting of wear test at optimum conditions (Load $-30 \mathrm{~N}$, Sliding speed $-2.4 \mathrm{~m} / \mathrm{s}$ and Sliding distance $-1000 \mathrm{~m}$ ), the morphological changes on the worn surface LM25, LM25 + 5 wt. percent SiC, LM $25+3$ wt. percent $\mathrm{Cu}$ and $\mathrm{LM} 25+5 \mathrm{wt}$. percent $\mathrm{SiC}+3 \mathrm{wt}$. percent $\mathrm{Cu}$ were examined through scanning electron microscope (SEM). The SEM image of LM25 (Fig. 4a) shows scratches and deep grooves along the sliding direction. The large amount of plastic deformation was also observed. The SEM image of LM $25+5$ wt. percent $\mathrm{SiC}$ (Fig. $4 \mathrm{~b}$ ) shows scratches but grooves becomes smaller than the LM25 alone. In the SEM images of LM $25+3$ percent $\mathrm{Cu}$ (Fig. 4c) scratches become smaller than the previous compositions. In the SEM image of $\mathrm{LM} 25+5$ percent $\mathrm{SiC}+3$ percent $\mathrm{Cu}$ (Fig. $4 \mathrm{~d}$ ), the degree of formation of cracks on the wear surface is not much. It exhibits relatively smoother MML and grooves due to delamination of mechanically mixed layer (MML).

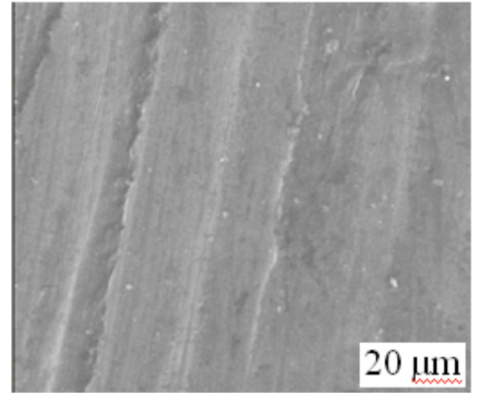

Fig 3. SEM micrographs of LM25/SiC/Cu hybrid Metal Matrix Composites.

This indicate the simultaneous occurrence of formation and delamination of MML. This is due to the properties of $\mathrm{SiC}$ and $\mathrm{Cu}$. From this, it is concluded that the less worn surface was identified in LM25 hybrid composite than the unreinforced LM25. This analysis proves that aluminium alloy's wear resistance can be improved with the addition of $\mathrm{SiC}$ and $\mathrm{Cu}$ reinforcements.

\section{Conclusions}

In the present work, the use of Taguchi's orthogonal array with grey relational analysis to optimize the multiple performance characteristics of LM25 hybrid composites such as wear rate and coefficient of friction has been reported. Based on the present experimental work, the following conclusions were drawn:

- The LM25 hybrid composites have been successfully produced by the stir casting route. The microstructural study clearly reveals a nearly uniform distribution of $\mathrm{SiC}$ and $\mathrm{Cu}$ in the LM25 matrix alloy.

- Grey relational analysis in the Taguchi method for the optimization of the multi response problems is a very useful tool for predicting the wear rate and coefficient of friction of $\mathrm{LM} 25 / \mathrm{SiC} / \mathrm{Cu}$ hybrid Metal Matrix Composites.

- From, ANOVA, it is revealed that the sliding velocity (44.08 percent) influences more on the multi-performance characteristics of LM25/SiC/Cu hybrid composite followed by load (28.14percent) and sliding distance (27.53percent).

- The wear rate is increased with load. The wear resistance of the alloy is improved significantly due to particle addition. The composite exhibited lower wear rate than that of the matrix alloy. 


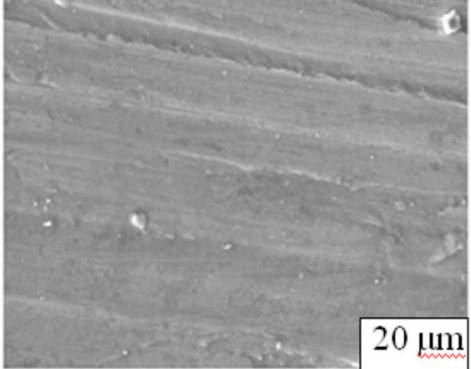

(a)

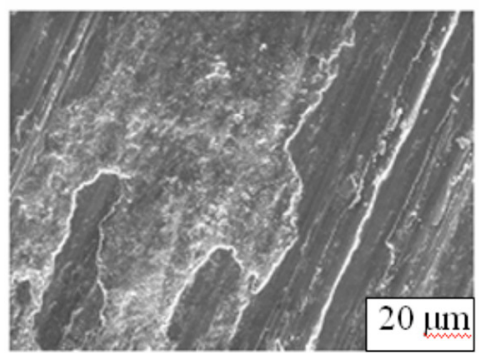

(c)

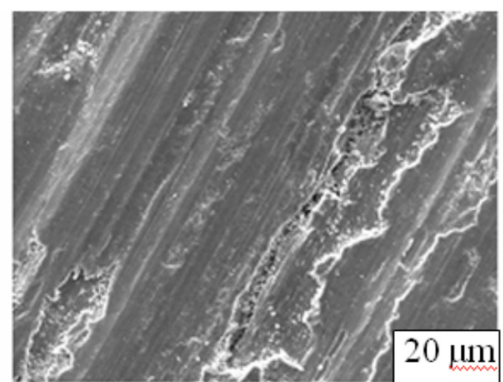

(b)

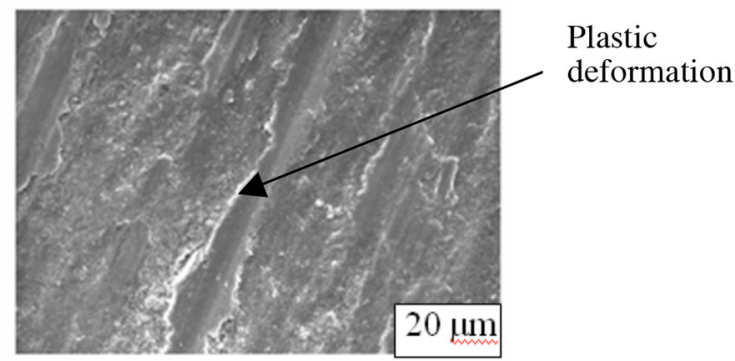

(d)

Fig. 4. SEM micrographs of the worn surfaces of (a) LM 25 (b) LM $25+5 \% \mathrm{SiC}$ (c) LM $25+3 \% \mathrm{Cu}$ (d) LM $25+5 \% \mathrm{SiC}+3 \% \mathrm{Cu}$ at $\mathrm{Load}-$ $30 \mathrm{~N}$, Sliding speed $-2.4 \mathrm{~m} / \mathrm{s}$ and Sliding distance $-1000 \mathrm{~m}$.

\section{References}

1. Z.Y. Liu, Q.Z. Wang, B.L. Xiao, Z.Y. Ma, Y. Liu, Experimental and modeling investigation on $\mathrm{SiCp}$ distribution in powder metallurgy processed $\mathrm{SiCp} / 2024 \mathrm{Al}$ composites, Mater. Sci. Eng. A 527 (2010) 5582-5591

2. B.K. Prasad, S.V. Prasad, A.A. Das, Abrasion-induced micro structural changes and material removal mechanisms in squeeze-cast aluminum alloy-silicon carbide composites, J. Mater. Sci. 27 (1992) 4489-4494

3. B.N.P. Bai, B.S. Ramasesh, M.K. Surappa, Dry sliding wear of A356-Al-SiCp composites, Wear 157 (1992) 295-304

4. C.S. Lee, Y.H. Kim, K.S. Han, T. Lim, Wear behaviour of aluminum matrix composite materials, J. Mater. Sci. 27 (1992) 793-800

5. A.P. Sannino, H.J. Rack, Dry sliding wear of discontinuously reinforced aluminum composites: review and discussion, Wear 189 (1995) 1-19

6. A. Sreenivasan, S. PaulVizhian, N.D. Shivakumar, M. Muniraj, M. Raguraman, A study of microstructure and wear behaviour of $\mathrm{TiB}_{2} / \mathrm{Al}$ metal matrix composites, Latin Am. J. Solids Struct. 8 (2011) 1-8

7. V. Gaitonde, S. Karnik, M. Jayaprakash, Some studies on wear and corrosion properties of AL5083/ $\mathrm{Al}_{2} \mathrm{O}_{3} /$ graphite hybrid composites, J. Miner. Mater. Character. Eng. 11 (2012) 695-703

8. K. Ravi Kumar, K.M. Mohanasundaram, G. Arumaikkannu, R. Subramanian, Analysis of parameters influencing wear and frictional behaviour of aluminium-fly ash composites, Tribology Trans. 55 (2012) 723-729

9. L. Zhang, X.B. He, X.H. Qu, B.H. Duan, X. Lu, M.L. Qin, Dry sliding wear properties of high volume fraction $\mathrm{SiCp} / \mathrm{Cu}$ composites produced by pressureless infiltration, Wear $\mathbf{2 6 5}$ (2008) 1848-1856
10. R. Shanawaz Patil, P. Madhu, B.P.G. Manjunath, M. Kalyana Kumar, Investigation of mechanical properties and wear behavior of Lm 25 Aluminum Alloy reinforced with silicon carbide and activated carbon, Int. J. Res. Sci. Innov. 5 (2018) 70-77

11. C. Ravi, G.B. Rudrakshi, S.M. Jigajinni, A study on dry sliding wear behaviour of Al-6061 redmud composite, Int. J. Innov. Res. Sci. Eng. Technol. 5 (2016) 7827-7832

12. P. Amuthakkannan, V. Manikandan, M. Ayyanar Raja, S. Rajesh, Wear characterization of aluminium/basalt fiber reinforced metal matrix composites - a novel material, Tribol. Ind. 39 (2017) 219-227

13. M. Arulraj, P.K. Palani, L. Venkatesh, Experimental investigation on dry sliding wear behaviour of hybrid metal matrix $\left(\mathrm{Al}-\mathrm{Al}_{2} \mathrm{O}_{3}-\mathrm{B}_{4} \mathrm{C}\right)$ composite, Int. J. ChemTech Res. 9 (2016) 359-364

14. H.B. Bhaskar, A. Sharief, Tribological properties of aluminium 2024 alloy-beryl particulate MMC's' bonfring, Int. J. Ind. Eng. Manag. Sci. 2 (2012) 143-147

15. J. Ahemad, R.A. Kapgate, N.D. Sadaphal, Y.H. Ahire, Tribological behavior of AL-LM25 and SiC, Int. Res. J. Eng. Technol. 2 (2015) 893-897

16. W. Narayan, Mannurkar, P.U. Raikar, Investigation of dry sliding wear behaviour of LM4 $(\mathrm{Al}-\mathrm{Si}$ and $\mathrm{Cu})-\mathrm{T} 6 / \mathrm{LM} 6$ (Al-Si12)-M using Taguchi approach, Int. Res. J. Eng. Technol. 2 (2015) 66-74

17. S. Mahdavi, F. Akhlaghi, Effect of $\mathrm{SiC}$ content on the processing, compaction behavior and properties of Al6061/ SiC/Gr hybrid composites, J. Mater. Sci. 46 (2011) 1502-1511

18. F. Akhlaghi, S. Mahdavi, Effect of the SiC content on the tribological properties of hybrid $\mathrm{Al} / \mathrm{Gr} / \mathrm{SiC}$ composites processed by in situ powder metallurgy (IPM) method, Adv. Mater. Res. 264-265 (2011) $1878-1886$ 
19. S. Das, S. Das, K. Das, Abrasive wear of zircon sand and alumina reinforced $\mathrm{Al}-4.5 \mathrm{wt}$. percent $\mathrm{Cu}$ alloy matrix composites - A comparative study, Compos. Sci. Technol. 67 (2007) 746-751

20. G. Ranganath, S.C. Sharma, M. Krishna, Dry sliding wear of garnet reinforced zinc/aluminium metal matrix composites, Wear 251 (2001) 1408-1413

21. K. Umanath, K. Palanikumar, S.T. Selvamani, Analysis of dry sliding wear behaviour of $\mathrm{Al} 6061 / \mathrm{SiC} / \mathrm{Al}_{2} \mathrm{O}_{3}$ hybrid metal matrix composites, Composites: Part B $\mathbf{5 3}$ (2013) 159-168.

22. C.P. Fung, Manufacturing process optimization for wear property of fibre-reinforced polybutylene terephthalate composites with grey relational analysis, Wear 254 (2003) 298-306

23. N. Tosun, C. Cogun, H. Pihtili, The effect of cutting parameters on wire crater sizes in wire EDM, Int. J. Adv. Manuf. Technol. 21 (2003) 857-865

Cite this article as: Poovalingam Muthu, Multi objective optimization of wear behaviour of Aluminum MMCs using GreyTaguchi method, Manufacturing Rev. 7, 16 (2020) 